\title{
Development and Validation of Stability Indicating RP-HPLC Method on Core Shell Column for Determination of Degradation and Process Related Impurities of Apixaban-An Anticoagulant Drug
}

\author{
Shashikant B. Landge1, Sanjay A. Jadhav', Sunil B. Dahale', Pavankumar V. Solanki', \\ Saroj R. Bembalkar ${ }^{2}$, Vijayavitthal T. Mathad ${ }^{*}$ \\ ${ }^{1}$ Department of Process Research and Development, Megafine Pharma (P) Ltd., Nashik, India \\ ${ }^{2}$ Department of Chemistry, Deogiri College, Aurangabad, India \\ Email: ${ }^{*}$ drvtmathad@yahoo.co.in, ${ }^{*}$ vt.mathad@megafine.in
}

Received 6 February 2015; accepted 9 May 2015; published 13 May 2015

Copyright (C) 2015 by authors and Scientific Research Publishing Inc.

This work is licensed under the Creative Commons Attribution International License (CC BY).

http://creativecommons.org/licenses/by/4.0/

(c) (i) Open Access

\section{Abstract}

A rapid, specific, sensitive, and precise reverse-phase HPLC method for the quantitative determination of process related and degradation impurities of Apixaban, an anticoagulant drug is described. The developed RP-HPLC method was successfully applied to the analysis of both Apixaban drug substance and drug product. The chromatographic separation was achieved on a Sigma-Aldrich's Ascentis Express ${ }^{\circledR} C_{18}(4.6 \mathrm{~mm} \times 100 \mathrm{~mm}, 2.7 \mu)$ HPLC column with a runtime of 40 min. Mobile phase-A and mobile phase- $B$ were phosphate buffer and acetonitrile respectively. The column oven temperature was set at $35^{\circ} \mathrm{C}$ and photodiode array detector was set at $225 \mathrm{~nm}$. Nine process related impurities (Imp-1 to Imp-9) have been detected in test sample of Apixaban by using newly developed RP-HPLC method. Forced degradation study was carried out under acidic, alkaline, oxidative, photolytic and thermal conditions to demonstrate the stability-indicating nature of the developed RP-HPLC method. The developed method was validated as per ICH guideline and found to be specific, precise, sensitive and robust.

\section{Keywords}

Apixaban, Core-Shell HPLC Columns, RSD and Validation, Stability Indicating

\footnotetext{
${ }^{*}$ Corresponding author.
}

How to cite this paper: Landge, S.B., et al. (2015) Development and Validation of Stability Indicating RP-HPLC Method on Core Shell Column for Determination of Degradation and Process Related Impurities of Apixaban-An Anticoagulant Drug. American Journal of Analytical Chemistry, 6, 539-550. http://dx.doi.org/10.4236/ajac.2015.66052 


\section{Introduction}

Apixaban is an anticoagulant drug chemically known as l-(4-methoxyphenyl)-7-oxo-6-[4-(2-oxopiperidin-l-yl) phenyl]-4,5,6,7-tetrahydro-lH-pyrazolo[3,4-c]pyridine-3-carboxamide and sold under the brand name "Eliquis" to treat the people with atrial fibrillation (a heart rhythm disorder) to lower the risk of stroke caused by a blood clot. It was invented by Aderis pharmaceuticals and was developed jointly by Pfizer and Bristol-Myers Squibb. Apixaban is a selective, reversible, direct inhibitor of factor Xa indicated to reduce the risk of stroke and systemic embolism in patients with non-valvular atrial fibrillation. "Eliquis" was approved both in US and Europe on Dec 2012 and Jan 2010 respectively. "Eliquis" is also used after hip or knee replacement surgery to prevent a type of blood clot called deep vein thrombosis (DVT), which can lead to blood clots in the lungs (pulmonary embolism) [1]-[6].

The development of an accurate and efficient analytical method to determine the quality of the product is a critical activity during the process development of the drug substance/product in generic pharmaceutical industries as process is either improved continuously with the use of new reagents: intermediates, etc., or route of synthesis itself changes some time to meet the economics. During the process research and development in our chemical laboratory, we identified nine process related impurities (Imp-1 to Imp-9) [7]. The analytical research development activities conducted to develop an efficient method using core shell chromatography column for the quantitative determination is presented in this article.

The silica particle used in UPLC column is porous with particle size of sub- $2 \mu$ which gives good resolution, speed and sensitivity but at the same time it gives high backpressure [8] [9]. The cost of investment for UPLC and its columns for routine analysis is higher than that of conventional HPLC and its columns. Hence core shell columns have been preferred to overcome these limitations [10]-[12].

Several analytical methods reported in the literature describe the investigation of pharmacokinetics of Apixaban wherein the content of Apixaban and/or its metabolites were studied in human plasma by liquid chromatography-mass spectrometry method [13]-[15] but failed to provide the details of process-related impurities and degradation related impurities formed under the stress conditions employed. One of the articles reported on stability indicating HPLC method for Apixaban bulk drug sample has been found to be non-selective at our end [16]. Further, Apixaban is not yet official in any of the pharmacopoeia. Hence, we felt the need for the development of a selective, fast and stability-indicating HPLC method on core shell column.

To the best of our knowledge, no method on core shell column has been reported for the determination of Apixaban and its potential process related impurities in the drug substance and drug product for regular analysis and stability studies in quality control laboratory. The core-objective of this research work was to develop a fast, precise, sensitive and stability-indicating RP-HPLC method for the determination of process and degradation related impurities of Apixaban. The developed method was successfully validated according to the USP <1225> Validation of Compendial Procedures and ICH guidelines [17] [18].

\section{Experimental}

\subsection{Materials and Reagents}

The gradient grade acetonitrile was procured from J. T. Baker, Mumbai, India. Ammonium dihydrogen orthophosphate, hydrochloric acid, sodium hydroxide and hydrogen peroxide were all of AR grade, procured from Merck (India). HPLC grade water obtained from Millipore system (Millipore Inc., USA) was used throughout the analysis. The test sample of Apixaban and its potential process related impurities viz., Imp-1, Imp-2, Imp-3, Imp-4, Imp-5, Imp-6, Imp-7, Imp-8 and Imp-9 (Figure 1) were received from synthetic laboratory of Megafine Pharma (P) Ltd., Nashik, India.

\subsection{Instrumentation and Chromatographic Conditions}

Agilent HPLC 1200 (Agilent Technologies, Germany) equipped with photodiode array detector was used for method development, forced degradation studies and method validation. Ascentis Express ${ }^{\circledR} \mathrm{C}_{18}(4.6 \mathrm{~mm} \times 100$ $\mathrm{mm}, 2.7 \mu$ ) HPLC column thermostated at $35^{\circ} \mathrm{C}$ was used for the separation. $0.02 \mathrm{M}$ ammonium dihydrogen orthophosphate buffer was prepared by dissolving $2.3 \pm 0.10 \mathrm{~g}$ ammonium dihydrogen orthophosphate in $1000 \mathrm{~mL}$ of water, filtered through $0.45 \mu \mathrm{m}$ membrane filter $(0.45 \mu$, Millipore) and degassed in ultrasonic bath prior to use as mobile phase A. Acetonitrile was used as mobile phase B. The flow rate and injection volumes were 1.0 

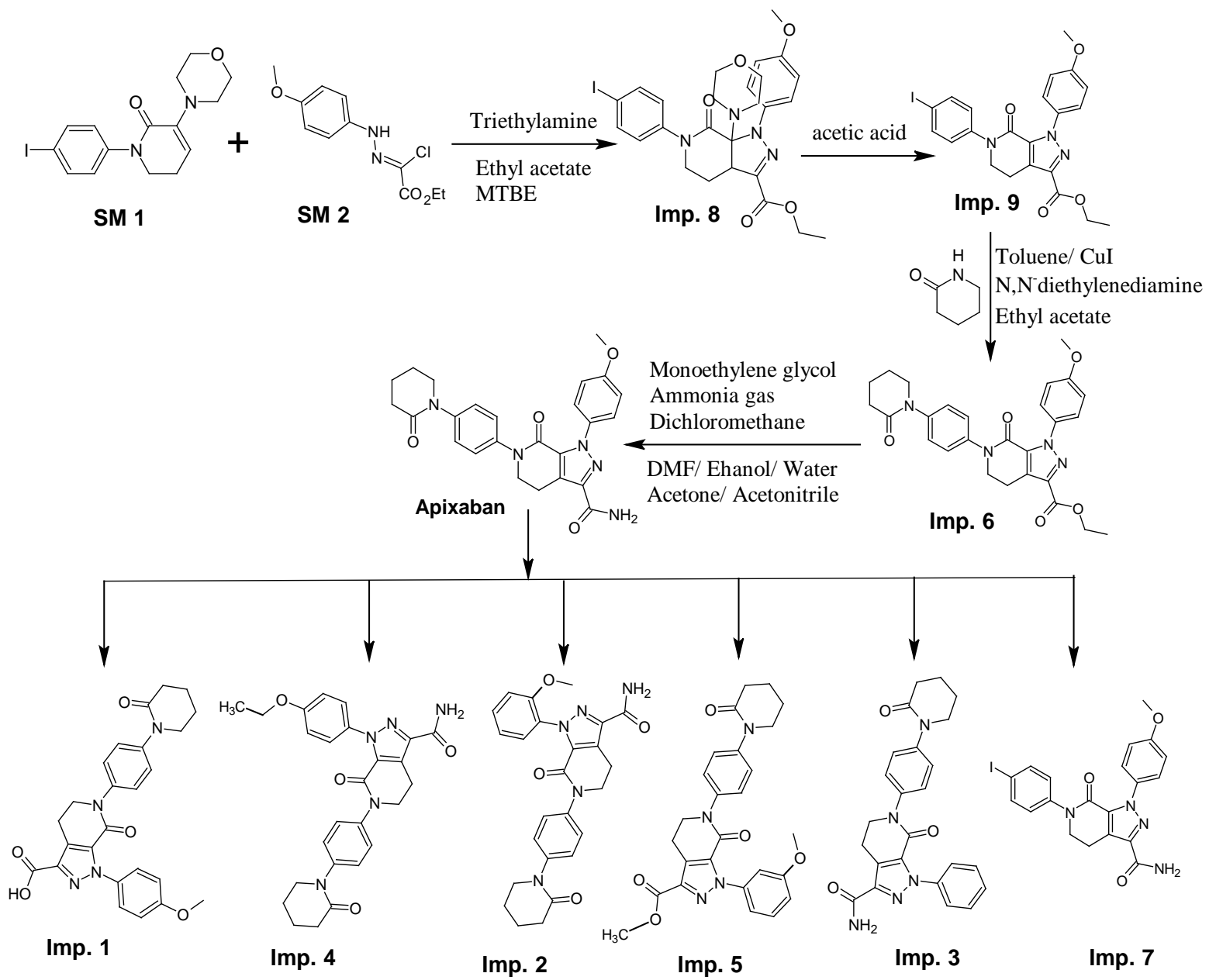

Figure 1. Process related impurities of Apixaban.

$\mathrm{mL} \cdot \mathrm{min}^{-1}$ and $10 \mu \mathrm{l}$ respectively. The analysis was carried out under the gradient condition as time $(\min ) / \mathrm{A}(\mathrm{v} / \mathrm{v})$ : $\mathrm{B}(\mathrm{v} / \mathrm{v}) ; \mathrm{T}_{0.01} / 80: 20, \mathrm{~T} 30.0 / 30: 70, \mathrm{~T}_{34.0} / 30: 70, \mathrm{~T}_{36.0} / 80: 20$ and $\mathrm{T}_{40.0} / 80: 20$. The data was acquired at $225 \mathrm{~nm}$ for 40 min and processed by using EZ Chrom Elite software Ver. 3.2.1. The photodiode array detector was used to determine the peak purity of stressed sample.

\subsection{Preparation of Solutions and Analytical Procedure}

A mixture of water and acetonitrile in the ratio of 70:30 (v/v) was used as diluent in the preparation of analytical solutions. The test sample solution having concentration of $500 \mu \mathrm{g} \cdot \mathrm{min}^{-1}$ was prepared for the determination of related substances. The stock solutions of each impurity (Imp-1 to Imp-9) at concentration about $150 \mu \mathrm{g} \cdot \mathrm{mL}^{-1}$ was prepared in diluent and further diluted to prepare the standard solution for quantification of impurities. The specification limits used for study was $0.15 \%$ for the related substances viz., Imp-1, Imp-2, Imp-3, Imp-4, Imp-5, Imp-6, Imp-7, Imp-8 and Imp-9. Apixaban standard solution $\left(500 \mu \mathrm{g} \cdot \mathrm{mL}^{-1}\right)$ spiked with all impurities at a specification level (w/w) was used as system suitability mixture (SSM). The blank, system suitability mixture, 6 replicates of standard and test solution were injected separately and chromatographed under the optimized chromatographic conditions. The resolution NLT 2.0, between Imp-2 and Imp-3 and \%RSD, NMT 5.0\% for areas obtained from six replicate injections of standard solution were set as system suitability criteria.

Formulation drug sample was prepared by powdering the tablets of Apixaban, dissolving an equivalent of $12.5 \mathrm{mg}$ of active ingredient in diluent in a $25-\mathrm{mL}$ volumetric flask and ultra sonicating for about 15 - 20 min followed by filtration through Merck Nylon syringe filter having pore size $0.45 \mu \mathrm{m}$. The clear liquid was collected and used for the determination of related substances in the pharmaceutical dosage forms. 


\section{Results and Discussion}

\subsection{Development of Chromatographic Conditions}

\subsubsection{Optimization of HPLC Chromatographic Conditions Using Core Shell Columns}

The objective of method development was to separate Apixaban and its process and degradation related impurities (Imp-1 to Imp-9) with shorter run time to increase the throughput at quality control laboratories, good resolution and peak shapes.

Initial method development trials were conducted on different stationary phases like $\mathrm{C}_{8}, \mathrm{C}_{18}$, Phenyl and Cyano along with the optimization of other chromatographic conditions like detection of wavelength, type and quantity of organic/inorganic buffer, $\mathrm{pH}$ of the mobile phase, thermostat and column oven temperature. Every time system suitability criteria were evaluated during the trial runs to ensure the strength of method. The resolution between Imp-2 and Imp-3 was critical and thus considered as the system suitability criteria. Satisfactory resolution and good peak shape of analyte was observed on Kromacil ${ }^{\circledR} \mathrm{C}_{18}(4.6 \mathrm{~mm} \times 250 \mathrm{~mm}, 5 \mu) \mathrm{HPLC}$ column at flow rate $1.0 \mathrm{~mL} \cdot \mathrm{min}^{-1}, \lambda 225 \mathrm{~nm}$, column oven temperature $35^{\circ} \mathrm{C}$ and injection thermostat $8^{\circ} \mathrm{C}$ and mobile phase was consisting phosphate buffer and acetonitrile with gradient elution mode. The silica particle present in conventional HPLC column (Kromacil ${ }^{\circledR} \mathrm{C}_{18}$ ) was porous in nature which results in higher back pressure and higher run time of method i.e. $60 \mathrm{~min}$. To reduce the run time, backpressure, good shape and resolution of impurities we conducted further screening using the core shell HPLC columns.

In core shell columns the modified silica particle having particle size of $2.7 \mu$ are used. Out of $2.7 \mu$, $1.7 \mu$ is a solid core and $1.0 \mu$ is diffusion core/path. In core shell columns mobile phase is passing through only $1.0 \mu$ diffusion path whereas in conventional HPLC column mobile phase is passing through $3 \mu / 5 \mu$ diffusion path (Figure 2). The core shell columns gives good peak shape, good resolution and theoretical plates due to less diffusion path to mobile phase. Thus we explored different core shell columns such as Ascentis Express ${ }^{\circledR} \mathrm{C}_{18}$ $(4.6 \mathrm{~mm} \times 100 \mathrm{~mm}, 2.7 \mu)$, Kinetex ${ }^{\circledR} \mathrm{C}_{18}(4.6 \mathrm{~mm} \times 100 \mathrm{~mm}, 2.7 \mu)$, Kinetex ${ }^{\circledR}$ Phenyl-hexyl $(4.6 \mathrm{~mm} \times 150 \mathrm{~mm}$, $5 \mu$ ), Kinetex ${ }^{\circledR} C_{8}(4.6 \mathrm{~mm} \times 150 \mathrm{~mm}, 5 \mu)$ and Kinetex ${ }^{\circledR}$ Biphenyl $(4.6 \mathrm{~mm} \times 150 \mathrm{~mm}, 5 \mu)$ during the development. Satisfactory peak shape, good resolution of Apixaban and its process and degradation related impurities and shorter run time (40 min) were achieved on Ascentis Express ${ }^{\circledR} \mathrm{C}_{18}(4.6 \mathrm{~mm} \times 100 \mathrm{~mm}, 2.7 \mu)$ column. Thus UPLC performance on conventional HPLC using core shell column/technique was achieved. All other chromatographic conditions remained similar to the conventional HPLC column (Kromacil ${ }^{\circledR} \mathrm{C}_{18}$ ) except injection volume which was changed from $20 \mu \mathrm{L}$ to $10 \mu \mathrm{L}$. The performance parameters of both the methods are shown in Table 1. It is observed that retention time of highly non polar peak (Imp-9) has been reduced from 50 min to 25 min. The typical chromatograms obtained from conventional HPLC column and core shell HPLC column are depicted in Figures 3-5.

\subsubsection{System Suitability Criteria}

The system suitability criteria were established based on several representative chromatograms. The column efficiency/theoretical plates should be more than 10,000; tailing factor should be less than 2.0 and \%RSD for six replicate injections of standard solution should be less than $5.0 \%$ were finalized as system suitability criteria. The separation between Imp-2 and Imp-3 with not less than 2.0 was fixed as resolution criterion. The developed method was complying system suitability criteria during the analytical method validation and batch analysis which itself indicate the good strength of developed analytical method. The results of system suitability criterion are depicted in Table 2.

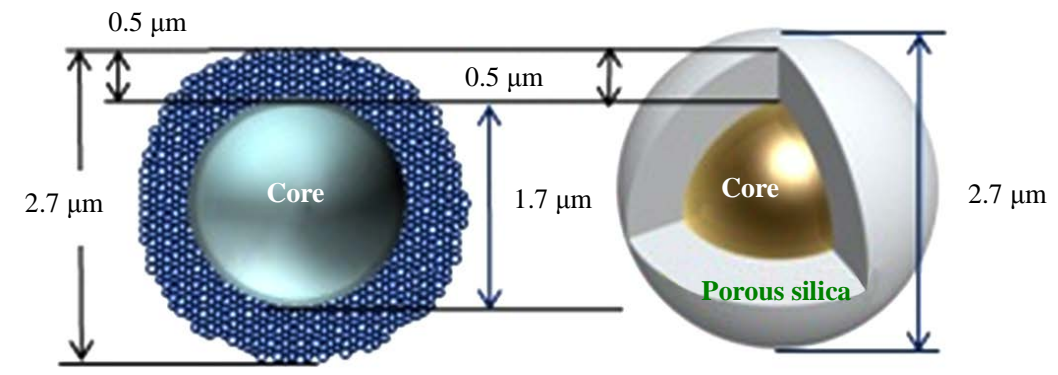

Figure 2. Systematic diagram of cores shell particle $(2.7 \mu)$. 
Table 1. Comparison of conventional column and core shell column.

\begin{tabular}{ccc}
\hline Parameter & Conventional HPLC column & Core shell HPLC column \\
\hline Elution time for Imp.9 (min) & 52.3 & 25.3 \\
Flow rate (mL/min) & 1.0 & 1.0 \\
Injection volume $(\mu \mathrm{L})$ & 20 & 10 \\
Run time (min) & 60 & 40 \\
Tailing Factor (for Imp.9) & 0.93 & 362,211 \\
USP Plate Count (for Imp.9) & 52,499 & 38 \\
\hline
\end{tabular}

(a) HPLC Chromatogram of Standard solution:

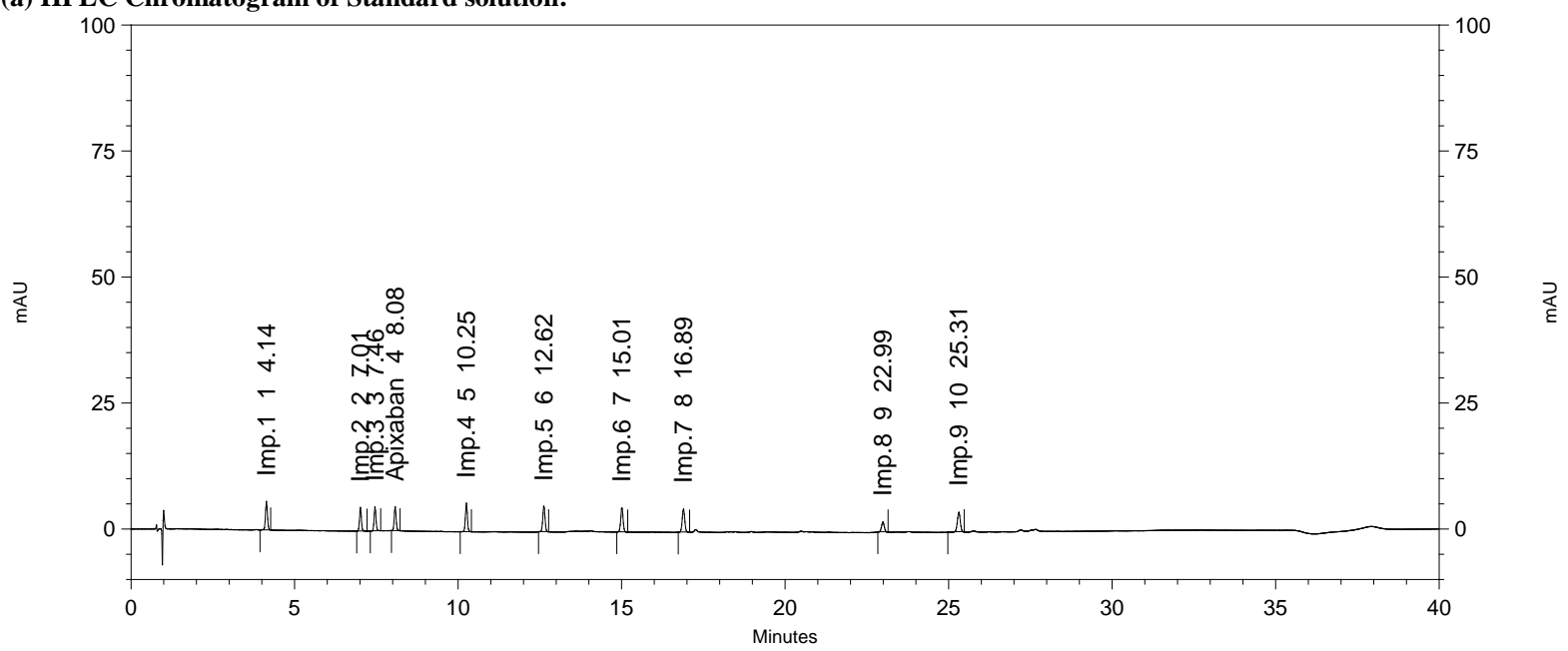

(b) HPLC Chromatogram of System suitability test solution (SST):

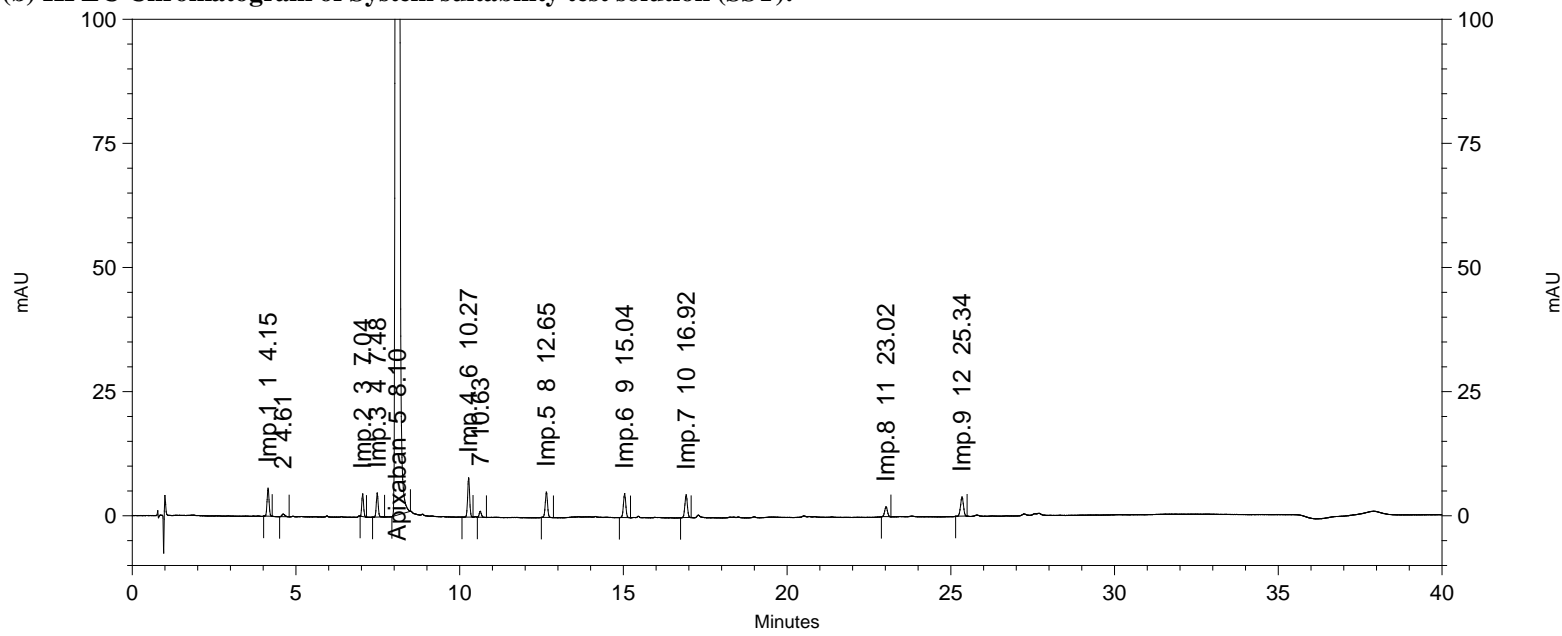

Figure 3. The chromatograms of Core shell column (a) standard solution and (b) SST.

\subsection{Validation}

\subsubsection{Specificity (Selectivity)}

Specificity is the ability of method to measure the analyte response in presence of its potential impurities. Stress testing of the drug substance can help to identify likely degradation products, which intern help to establish the degradation pathways and intrinsic stability of the molecule and validate the stability-indicating power of the analytical procedures used. 
(a) HPLC Chromatogram of test solution spiked with Impurities at $1.0 \% \mathrm{w} / \mathrm{w}$ :

(Conventional HPLC column)

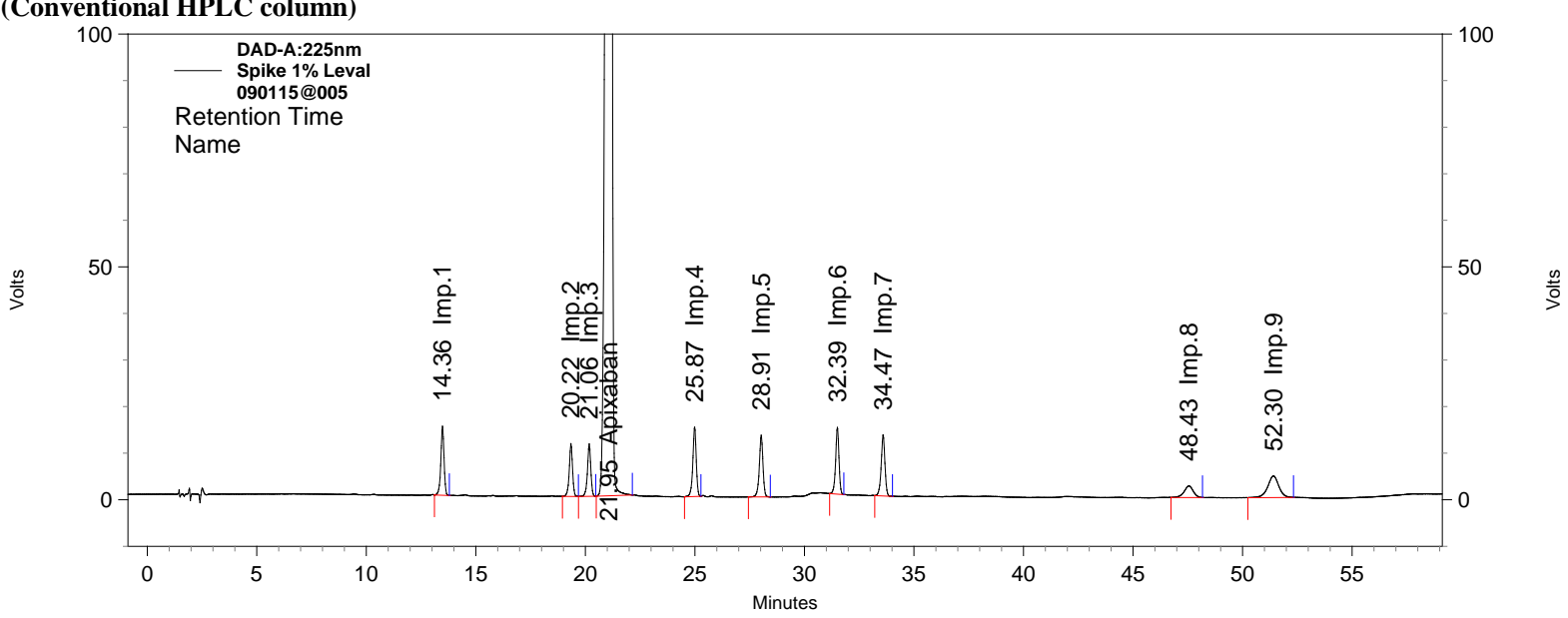

(b) HPLC Chromatogram of test solution spiked with Impurities at $1.0 \% \mathrm{w} / \mathrm{w}$ :

(Core shell HPLC column):

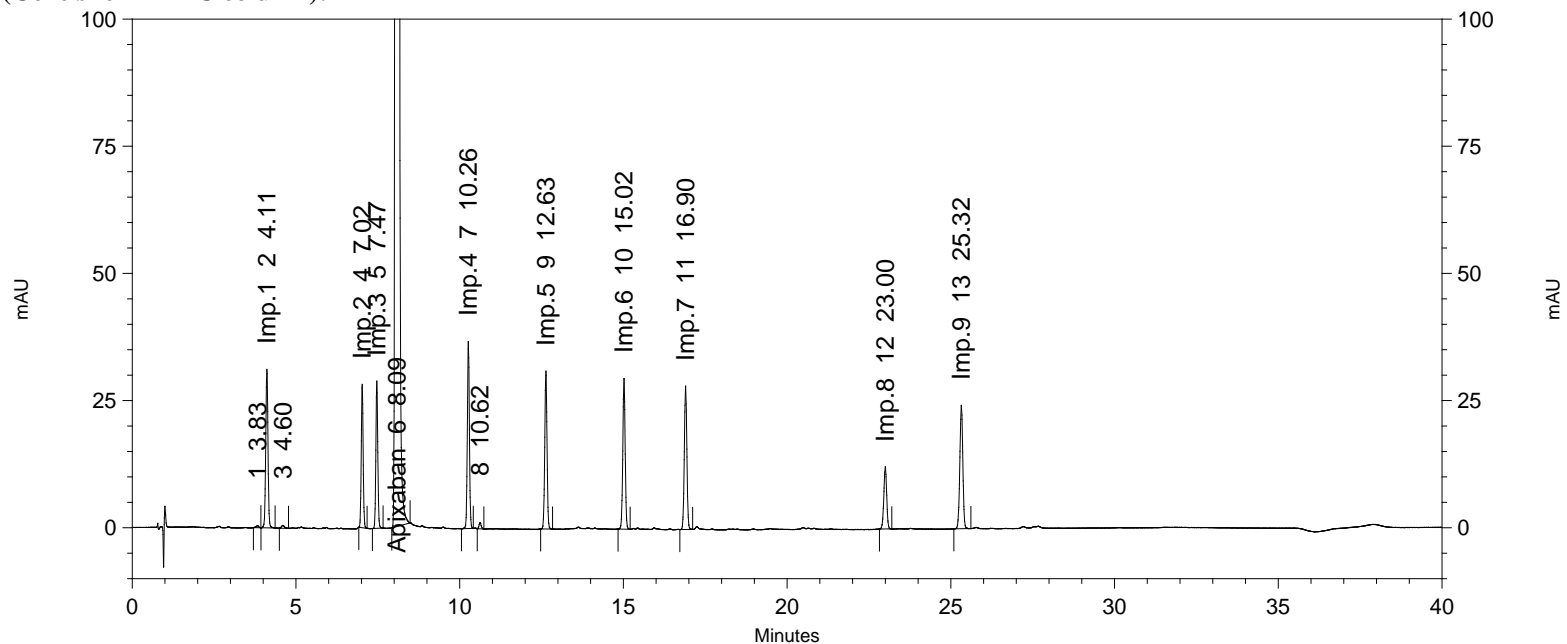

Figure 4. Comparison of the chromatograms of test solution spiked (a) Conventional HPLC column and (b) Core shell HPLC column.

The specificity of developed RP-HPLC method for Apixaban was determined in presence of its impurities (Imp-1 to Imp-9) and degradation products. Forced degradation studies were also performed on Apixaban to provide an indication of the stability-indicating property and specificity of the proposed method. The degradation study was performed by exposing the sample to different stress conditions such as light (1.2 million lux hours), heat $\left(105^{\circ} \mathrm{C}\right.$ for 7 days), acid hydrolysis ( $1 \mathrm{M} \mathrm{HCl}$ for $\left.24 \mathrm{hrs}\right)$, base hydrolysis (1 M NaOH for 2 hrs) and oxidation (15\%v/v $\mathrm{H}_{2} \mathrm{O}_{2}$ for $\left.24 \mathrm{hrs}\right)$. The significant degradation was observed in acid and alkali solution as shown in Figure 6.

The mass balance was calculated for all the stressed samples. The mass balance is a process of adding together the assay value and the levels of degradation products to see how closely these add up to $100 \%$ of initial value with due consideration of the margin of analytical error [19]-[21]. Aphotodiode array detector was employed to check and ensure the homogeneity and purity of Apixaban peak in all the stressed sample solutions. The results of forced degradation study are depicted in Table 3 .

\subsubsection{Linearity}

The linearity of peak areas versus different concentrations was evaluated for Apixaban and its related impurities by using the six levels ranging from LOQ to $250 \%$ (LOQ, $0.187 \mu \mathrm{g} \cdot \mathrm{mL}^{-1}, 0.375 \mu \mathrm{g} \cdot \mathrm{mL}^{-1}, 0.75 \mu \mathrm{g} \cdot \mathrm{mL}^{-1}, 1.125$ 
(a) Un-spiked test preparation:

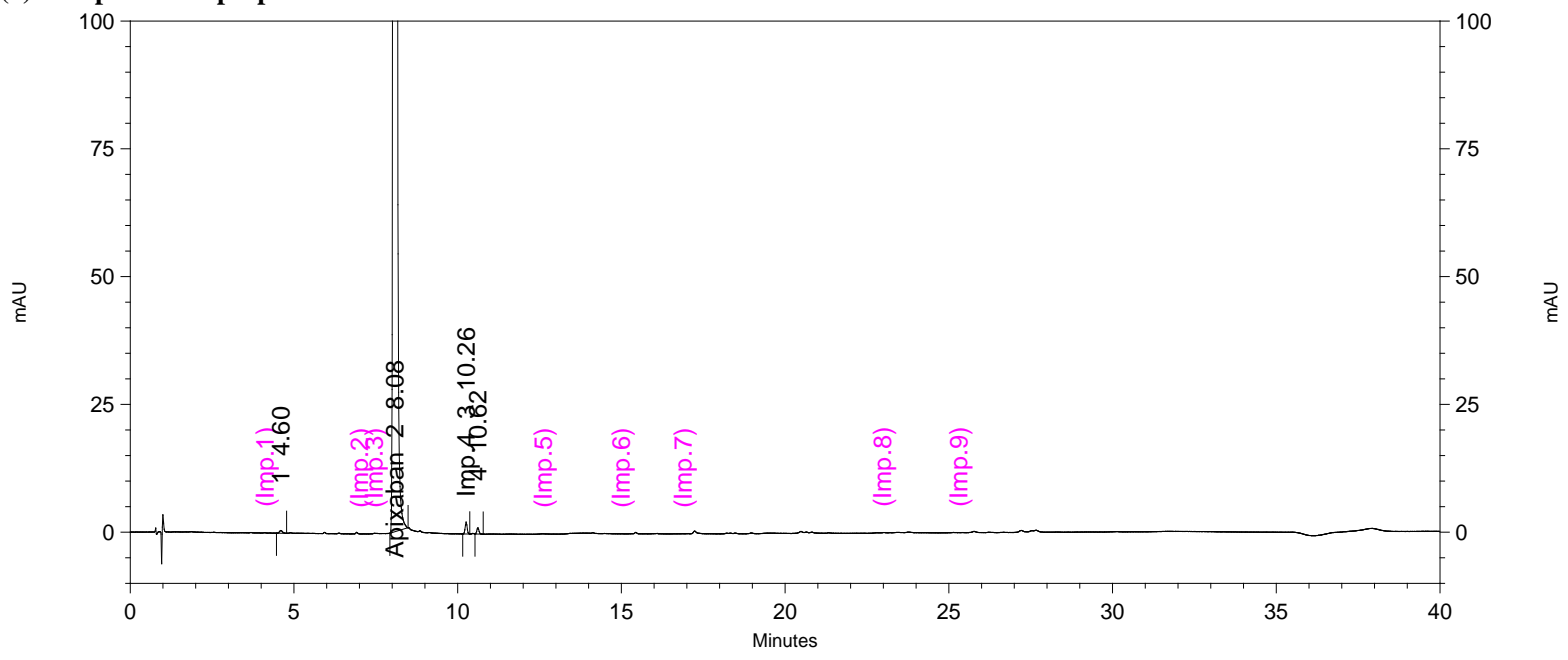

(b) Spiked test preparation:

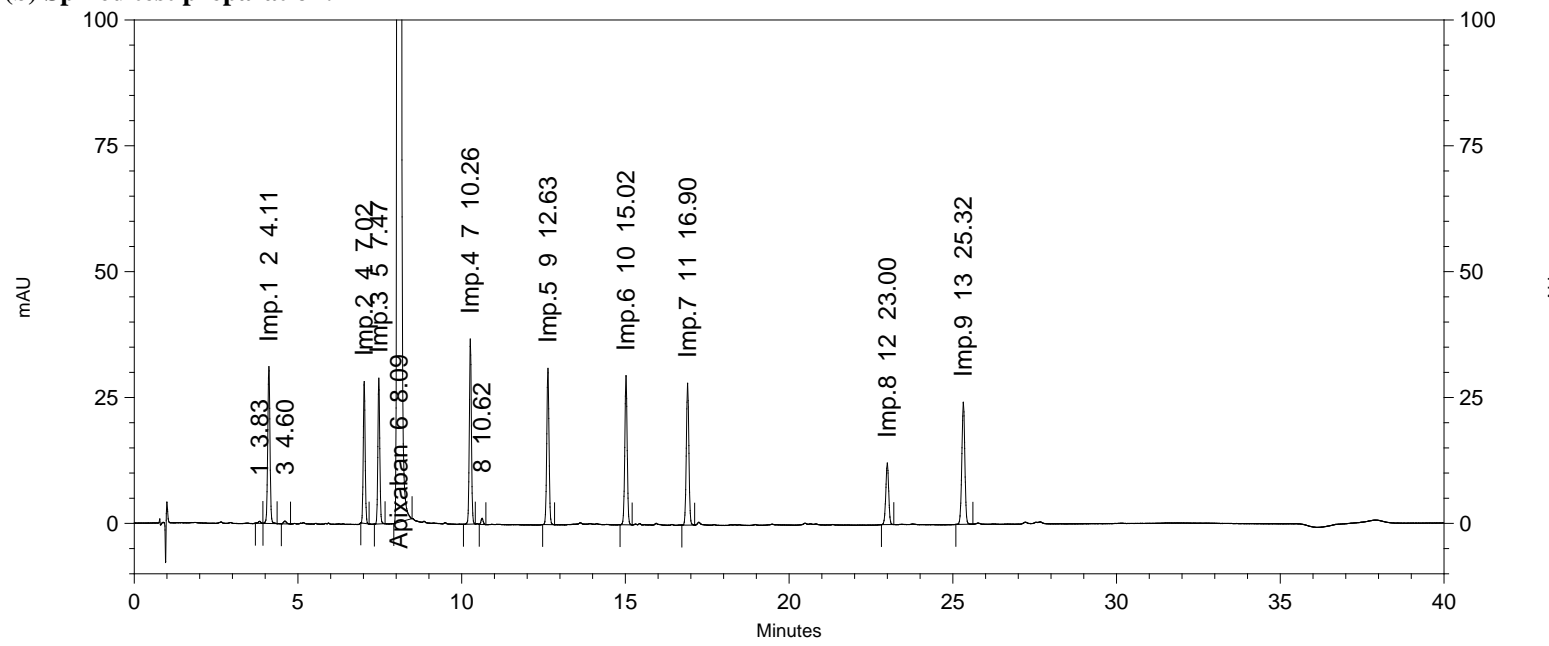

Figure 5. Typical HPLC chromatograms of; (a) Apixaban, un-spiked test preparation; (b) Apixaban spiked test preparation with known impurities (Imp-1 to Imp-9).

Table 2. System suitability test results.

\begin{tabular}{cccccccc}
\hline Compound & Capacity factor $(\mathbf{k})$ & Selectivity $(\boldsymbol{\alpha})$ & Resolution $\left(\mathbf{R}_{\mathbf{s}}\right)$ & Tailing factor $(\mathbf{T})$ & Theoretical plates & RRT \\
\hline Imp-1 & 40.40 & 2.87 & - & 1.04 & 22448 & 0.51 \\
Imp-2 & 69.13 & 0.45 & 26.63 & 1.06 & 1.07 & 71004 & 0.87 \\
Imp-3 & 73.60 & 0.62 & 4.22 & 1.05 & 78696 & 0.92 \\
Apixaban & 79.77 & 2.17 & 5.76 & 1.05 & 130016 & 1.00 \\
Imp-4 & 101.53 & 2.37 & 19.67 & 1.01 & 156264 & 1.27 \\
Imp-5 & 125.23 & 2.39 & 19.64 & 1.01 & 201784 & 1.86 \\
Imp-6 & 149.10 & 1.88 & 18.26 & 1.02 & 223135 & 2.09 \\
Imp-7 & 167.93 & 6.10 & 13.61 & 0.97 & 317500 & 2.85 \\
Imp-8 & 228.93 & 2.32 & 39.83 & 14.03 & 0.97 & 365015 & 3.13 \\
Imp-9 & 252.13 & - & &
\end{tabular}

RRT (Relative retention time). 
(a) Acid treated test sample

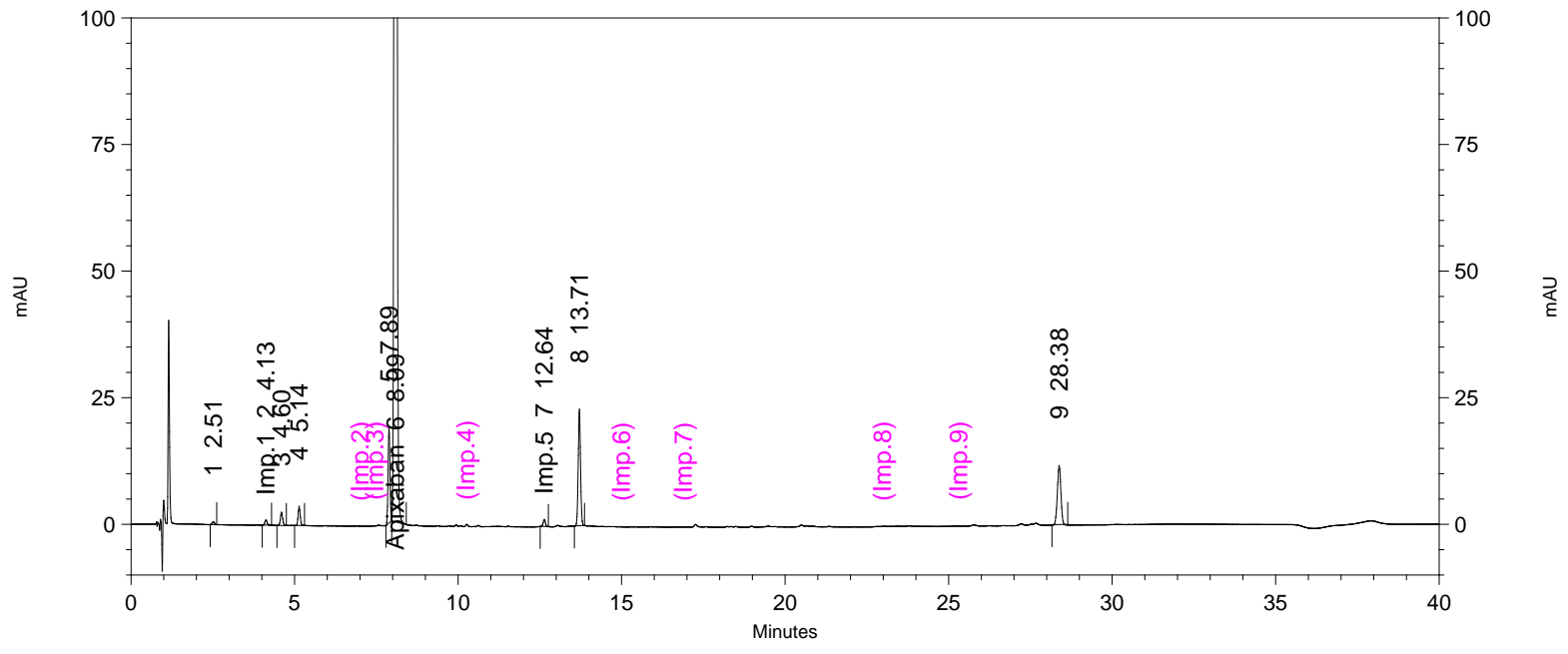

(b) Base treated test sample

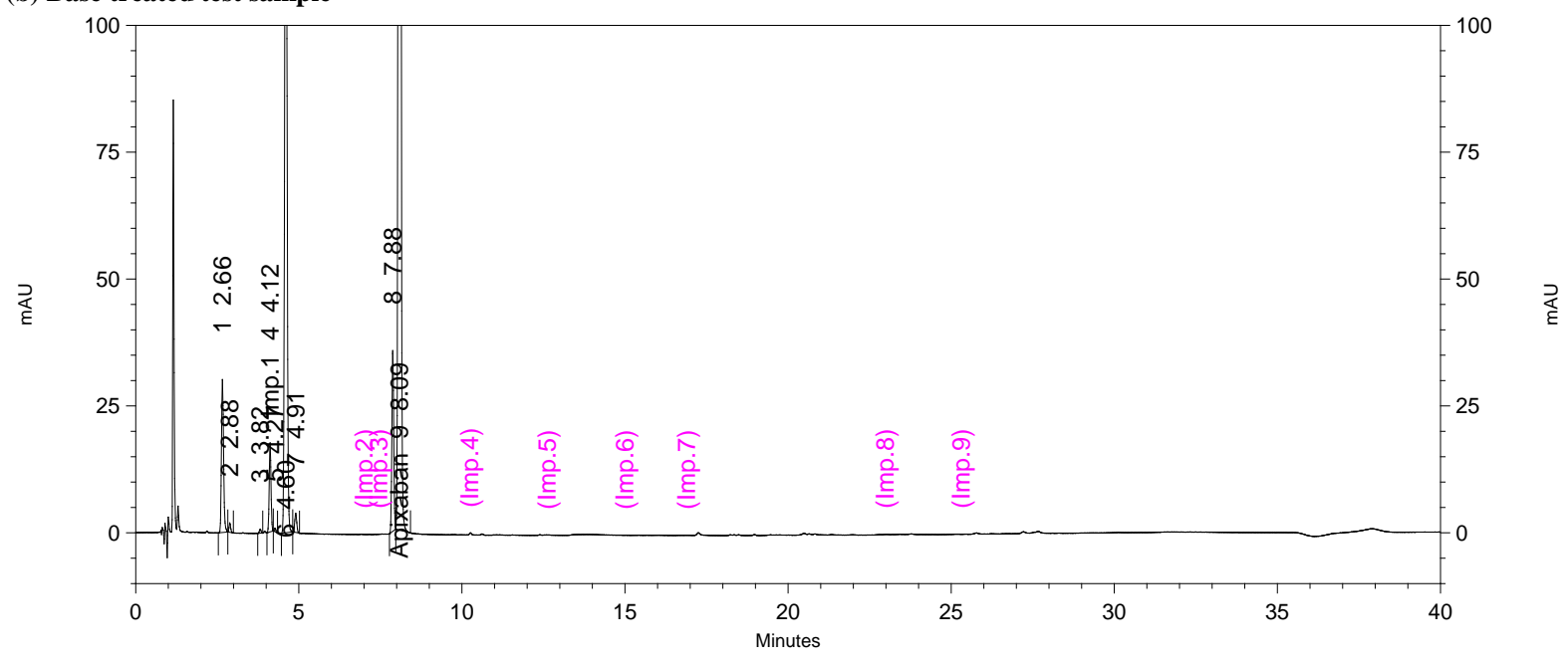

Figure 6. Typical HPLC chromatograms of forced degradation study (a) Acid treated test sample, (b) Base treated test sample.

Table 3. Forced degradation results.

\begin{tabular}{|c|c|c|c|c|}
\hline Stress condition & $\%$ of Apixaban & $\%$ of degredants & Observation and mass balance & Peak purity \\
\hline Un-degraded & 100 & - & - & 1.0000 \\
\hline $\begin{array}{l}\text { Acid hydrolysis } \\
\text { (1 M HCl, } 24 \text { h at Room Temp.) }\end{array}$ & 90.91 & 9.09 & $\begin{array}{l}\text { Major unknown degradation product } \\
\text { (3.2\%) formed (Mass balance: } 102.03 \%)\end{array}$ & 1.0000 \\
\hline $\begin{array}{l}\text { Base hydrolysis } \\
\text { (1 M NaOH, } 2 \text { h at Room Temp.) }\end{array}$ & 71.25 & 28.75 & $\begin{array}{l}\text { Major unknown degradation product } \\
\text { (20.06\%) formed (Mass balance: } 101.55 \%)\end{array}$ & 1.0000 \\
\hline $\begin{array}{l}\text { Oxidation } \\
\left(15 \% \mathrm{H}_{2} \mathrm{O}_{2}, 24 \text { h. at Room Temp.) }\right.\end{array}$ & 99.43 & 0.57 & $\begin{array}{l}\text { No any known and unknown major degradation } \\
\text { product formed (Mass balance: } 101.78 \% \text { ) }\end{array}$ & 1.0000 \\
\hline $\begin{array}{l}\text { Thermal } \\
\left(105^{\circ} \mathrm{C}, 7 \text {-days }\right)\end{array}$ & 100 & Nil & $\begin{array}{l}\text { No any known and unknown degradation } \\
\text { product formed (Mass balance: 98.69\%) }\end{array}$ & 1.0000 \\
\hline Photolytic as per ICH & 100 & Nil & $\begin{array}{l}\text { No any known and unknown degradation } \\
\text { product formed (Mass balance: 98.07\%) }\end{array}$ & 1.0000 \\
\hline
\end{tabular}

Mass balance $=\%$ assay $+\%$ sum of all impurities $+\%$ sum of all degredants . 
$\mu \mathrm{g} \cdot \mathrm{mL}^{-1}$ and $1.50 \mu \mathrm{g} \cdot \mathrm{mL}^{-1}$ ) with respect to specification level of impurities. The linear regression data for all the components tested is presented in Table 4.

\subsubsection{Limits of Detection and Quantification (LOD and LOQ)}

According to ICH Q2 (R1) recommendations the limits of detection (LOD) and the limit of quantification (LOQ) for Apixaban and its process related impurities (Imp-1 to Imp-9) were estimated by calibration curve method [standard deviation of the response $(\sigma)$ and the slope (S)], by injecting the series of dilute solutions of known concentration. The values of LOD and LOQ for impurities and Apixaban were found to be in the range of $0.014 \%-0.038 \%$ and $0.010 \%-0.015 \%$ respectively. Precision was studied at the LOQ level by injecting six individual preparations of Apixaban and its nine process related impurities, followed by the calculation of \%RSD of the peaks areas. The \%RSD of LOQ precision was in the range of $1.86 \%-4.66 \%$.The results are depicted in Table 4.

\subsubsection{Precision}

The precision of method is degree of agreement between the results. Precision of the method was studied for system precision, method precision and intermediate precision. A standard solution of Apixaban was injected for six times to determine the system precision of the method and \%RSD was calculated for Apixaban and its all process related impurities. The \%RSD of system precision was found between $0.28 \%$ to $2.18 \%$.

Six separate test sample solutions of Apixaban were prepared by spiking the related impurities (Imp- 1 to Imp-9) at specification level for measuring the method precision. The \%RSD $(n=6)$ for each related impurities was evaluated and found in between $0.72 \%$ to $2.44 \%$. The similar procedure of method precision was carried out by a different analyst, using different mobile phase and diluent preparations and instrument on a different day with different lot of same brand column for intermediate precision study. The \%RSD of results for intermediate precision study was calculated and compared with the method precision results.

\subsubsection{Accuracy (Recovery)}

Accuracy of the method for all the related substances was determined by analyzing Apixaban sample solutions spiked with all the related substances at four different concentration levels of LOQ, 50,100 and 150\% of each in triplicate at the specified limit. The recovery of all these related substances were found to be in-between the predefined acceptance criterion of $80.0 \%-120.0 \%$ and the data is given in Table 5 .

Table 4. Linearity, Limit of detection (LOD) and Limit of quantitation (LOQ) data.

\begin{tabular}{|c|c|c|c|}
\hline \multirow{2}{*}{ Component } & \multicolumn{2}{|c|}{ LOD/LOQ results } & \multirow{2}{*}{ Linearity } \\
\hline & LOQ $\mu g / m L,(\% \text { w.r.t. })^{c}$ & LOD $\mu g / m L,(\% \text { w.r.t. })^{c}$ & \\
\hline Imp-1 & $0.111(0.022)$ & $0.074(0.015)$ & 0.99989 \\
\hline Imp-2 & $0.108(0.022)$ & $0.072(0.015)$ & 1.00000 \\
\hline Imp-3 & $0.106(0.021)$ & $0.071(0.014)$ & 0.99954 \\
\hline Apixaban & $0.075(0.015)$ & $0.050(0.010)$ & 0.99979 \\
\hline Imp-4 & $0.111(0.022)$ & $0.074(0.015)$ & 0.99969 \\
\hline Imp-5 & $0.113(0.022)$ & $0.075(0.015)$ & 0.99981 \\
\hline Imp-6 & $0.113(0.022)$ & $0.075(0.015)$ & 0.99978 \\
\hline Imp-7 & $0.107(0.022)$ & $0.071(0.014)$ & 0.99975 \\
\hline Imp-8 & $0.188(0.038)$ & $0.113(0.023)$ & 0.99882 \\
\hline Imp-9 & $0.117(0.023)$ & $0.078(0.016)$ & 0.99963 \\
\hline
\end{tabular}

${ }^{c} \mathrm{LOD}$ LOQ values are in \% with respect to test concentration of $500 \mu \mathrm{g} / \mathrm{mL}$. 
Table 5. Accuracy data of related substances.

\begin{tabular}{|c|c|c|c|c|}
\hline \multirow[b]{2}{*}{ Component } & \multicolumn{4}{|c|}{ Recovery results (Mean \% Recovery \pm \% RSD) } \\
\hline & $\begin{array}{c}\text { LOQ level; } \\
\text { amount (\%w/w) }\end{array}$ & $\begin{array}{c}50 \% \text { of specification level }{ }^{\mathrm{b}} \text {; } \\
\text { amount }(\% \mathrm{w} / \mathrm{w})\end{array}$ & $\begin{array}{c}100 \% \text { of specification level } \\
\text { amount }(\% \mathrm{w} / \mathrm{w})\end{array}$ & $\begin{array}{c}150 \% \text { of specification level } \\
\text { amount }(\% \mathrm{w} / \mathrm{w})\end{array}$ \\
\hline Imp-1 & $107.58 \pm 2.44$ & $98.63 \pm 1.39$ & $98.64 \pm 1.38$ & $97.88 \pm 0.72$ \\
\hline Imp-2 & $98.41 \pm 2.79$ & $84.72 \pm 0.00$ & $88.86 \pm 0.78$ & $91.02 \pm 0.62$ \\
\hline Imp-3 & $112.70 \pm 2.44$ & $102.83 \pm 2.74$ & $99.53 \pm 1.65$ & $97.79 \pm 0.28$ \\
\hline Imp-4 & $104.55 \pm 4.35$ & $95.43 \pm 0.83$ & $94.31 \pm 0.86$ & $94.69 \pm 0.73$ \\
\hline Imp-5 & $101.52 \pm 2.59$ & $103.15 \pm 5.45$ & $97.76 \pm 2.41$ & $96.12 \pm 2.30$ \\
\hline Imp-6 & $101.52 \pm 2.59$ & $97.32 \pm 0.02$ & $96.87 \pm 1.06$ & $97.76 \pm 0.79$ \\
\hline Imp-7 & $112.70 \pm 2.44$ & $100.48 \pm 0.82$ & $97.63 \pm 1.11$ & $96.54 \pm 0.57$ \\
\hline Imp-8 & $95.49 \pm 6.54$ & $107.14 \pm 0.69$ & $96.64 \pm 1.39$ & $93.75 \pm 0.51$ \\
\hline Imp-9 & $103.03 \pm 2.55$ & $97.78 \pm 0.79$ & $96.42 \pm 1.07$ & $96.43 \pm 0.81$ \\
\hline
\end{tabular}

${ }^{\mathrm{a}} \%$ Recovery average of three determinations; ${ }^{\mathrm{b}} 0.15 \%$ of all related substances.

\subsubsection{Stability of Analytical Solution}

The sample solutions of Apixaban spiked with all related impurities at specified level were prepared and analyzed immediately and after different time intervals up to 48 hrs to determine the stability of sample solution. The sample cooler temperature was maintained at about $25^{\circ} \mathrm{C}$ and at about refrigerator temperature $\left(8^{\circ} \mathrm{C}\right)$. The results from these studies indicated that the sample solution was unstable at room temperature and stable for 48 hrs at $8^{\circ} \mathrm{C}$.

\subsubsection{Robustness}

The chromatographic conditions were deliberately altered to evaluate the robustness of developed method. The resolution between closely eluting peak pair i.e. Imp-2 and Imp-3 was evaluated on altered chromatographic condition. To study the effect of flow rate on the resolution, the flow rate of mobile phase was altered by \pm 0.1 $\mathrm{mL} \cdot \mathrm{min}^{-1}$ (0.9 to $1.1 \mathrm{~mL} \cdot \mathrm{min}^{-1}$ from $\left.1.0 \mathrm{~mL} \cdot \mathrm{min}^{-1}\right)$. The effect of column temperature on resolution was studied at $32^{\circ} \mathrm{C}$ and $38^{\circ} \mathrm{C}$ instead of $35^{\circ} \mathrm{C}$ whereas all other mobile phase components were held constant as described above. The tailing factor of Apixaban was less than 2.0 and the resolution between Imp- 2 and Imp-3 was greater than 2.0 in all the deliberate varied chromatographic conditions indicating the robustness of the method.

\subsubsection{Application of the Method}

The analysis of commercial formulation sample and bulk drug sample indicated that the method is specific and selective for determination of related substances in the formulation and bulk drug samples (Table 6). The developed method is capable for quantitative analysis of Apixaban the bulk drug and in a pharmaceutical dosage form.

\section{Conclusion}

This is the first method reported in the literature for the separation and quantification of Apixaban and its process related and degradation related impurities on core shell column. The RP-HPLC method is fast, specific, linear, sensitive, accurate, precise, and robust. Moreover, the developed method was found to be more selective and rapid with respect to shorter runtime and low back pressure as compared to conventional HPLC column method. Method is validated as per ICH requirements and based on solution stability study the auto sampler cooler temperature needs to be maintained at $8^{\circ} \mathrm{C}$ during analysis. The developed method is stability indicating method which can be used for the analysis of routine and stability samples of Apixaban drug substance and drug products. 
Table 6. Results of formulated tablet analysis and bulk drug batches sample analysis.

\begin{tabular}{|c|c|c|c|c|c|}
\hline \multirow{2}{*}{ Component } & \multicolumn{3}{|c|}{ Bulk drug sample batches } & \multicolumn{2}{|c|}{ Formulation sample } \\
\hline & Batch No. 1 & Batch No. 2 & Batch No. 3 & Sample-1 & Sample-2 \\
\hline Imp-1 & ND & ND & ND & 0.04 & 0.04 \\
\hline Imp-2 & 0.03 & ND & ND & ND & ND \\
\hline Imp-3 & ND & ND & ND & 0.03 & 0.03 \\
\hline Apixaban & 99.71 & 99.8 & 99.89 & 99.59 & 99.39 \\
\hline Imp-4 & 0.07 & 0.04 & 0.06 & ND & ND \\
\hline Imp-5 & ND & ND & ND & ND & ND \\
\hline Imp-6 & ND & 0.03 & ND & ND & ND \\
\hline Imp-7 & ND & ND & ND & ND & ND \\
\hline Imp-8 & ND & ND & ND & ND & ND \\
\hline Imp-9 & ND & ND & ND & 0.15 & 0.15 \\
\hline
\end{tabular}

ND: Not detected.

\section{Acknowledgements}

The authors wish to thank the management of Megafine Pharma (P) Ltd., for supporting this work. The author is also thankful to colleagues in the division of Research and Development of Megafine Pharma (P) Ltd. for their cooperation in carrying out this work.

\section{References}

[1] http://www.rxlist.com/eliquis-drug.htm

[2] Pujadas, M.L., Escolar, G., Arellano-Rodrigo, E. and Galan, A. (2013) Apixaban in the Prevention of Stroke and Systemic Embolism in Nonvalvular Atrial Fibrillation. Drugs Today (Barc), 49, 425-436.

[3] Frost, C., Wang, J. and Nepal, S. (2013) Apixaban, an Oral, Direct Factor Xa Inhibitor: Single Dose Safety, Pharmacokinetics, Pharmacodynamics and Food Effect in Healthy Subjects. British Journal of Clinical Pharmacology, 75, 476487.

[4] Turpie, A.G. (2007) Oral, Direct Factor Xa Inhibitors in Development for the Prevention and Treatment of Thromboembolic Diseases. Arteriosclerosis Thrombosis and Vascular Biology, 27, 1238-1247.

[5] Lassen, M.R., Davidson, B.L., Gallus, A., Pineo, G., Ansell, J. and Deitchman, D. (2007) The Efficacy and Safety of Apixaban, an Oral, Direct Factor Xa Inhibitor, as Thromboprophylaxis in Patients Following Total Knee Replacement. Journal of Thrombosis and Haemostasis, 5, 2368-2375.

[6] Lassen, M.R., Gallus, A., Raskob, G.E., Pineo, G., Chen, D. and Ramirez, L.M. (2010) Apixaban versus Enoxaparin for Thromboprophylaxis after Hip Replacement. The New England Journal of Medicine, 363, 2487-2498.

[7] Solanki, P.V., Uppelli, S.B., Dhokrat, P.V. and Mathad, V.T. (2015) Investigation on Polymorphs of Apixaban, an Anticoagulant Drug: Study of Their Transformations and Designing Efficient Process for Their Preparation. World Journal of Pharmaceutical Science, 3, 663-677.

[8] Wren, S.A.C. and Tchelitcheff, P. (2006) Use of Ultra-Performance Liquid Chromatography in Pharmaceutical Development. Journal of Chromatography A, 1119, 140-146.

[9] Snyder, L.R., Kirkland, J.J. and Dolan, J.W. (1997) Introduction to Modern Liquid Chromatography.

[10] Cunliffe, J.M. and Maloney, T.D. (2007) Fused-Core Particle Technology as an Alternative to Sub-2-Micron Particles to Achieve High Separation Efficiency with Low Backpressure. Journal of Separation Science, 30, 3104-3109.

[11] Samanidou, V.F. (2013) Core-Shell Particle Technology in Pharmaceutical Analysis. Pharmaceutica Analytica Acta, 4, e148. http://dx.doi.org/10.4172/2153-2435.1000e148

[12] http://www.phenomenex.com/Kinetex/CoreShellTechnology

[13] Delavenne, X., Mismetti, P. and Basset, T. (2013) Rapid Determination of Apixaban Concentration in Human Plasma 
by Liquid Chromatography/Tandem Mass Spectrometry: Application to Pharmacokinetic Study. Journal of Pharmaceutical and Biomedical Analysis, 150, 78-79.

[14] Pursley, J., Shen, J.X., Schuster, A., Dang, O.T., Lehman, J., Buonarati, M.H., Song, Y., Aubry, A.F. and Arnold, M.E. (2014) LC-MS/MS Determination of Apixaban (BMS-562247) and Its Major Metabolite in Human Plasma: An Application of Polarity Switching and Monolithic HPLC Column. Bioanalysis, 6, 2071-2082.

[15] Gous, T., Couchman, L., Patel, J.P., Paradzai, C., Arya, R. and Flanagan, R.J. (2014) Measurement of the Direct Oral Anticoagulants Apixaban, Dabigatran, Edoxaban, and Rivaroxaban in Human Plasma Using Turbulent Flow Liquid Chromatography with High-Resolution Mass Spectrometry. Therapeutic Drug Monitoring, 36, 597-605.

[16] Prabhune, S.S., Jaguste, R.S., Kondalkar, P.L. and Pradhan, N.S. (2014) Stability-Indicating High Performance Liquid Chromatographic Determination of Apixaban in the Presence of Degradation Products. Scientia Pharmaceutica, 82, 777-785.

[17] The United States Pharmacopeia (2015) Validation of Compendial Methods. USP38 NF-33, Chapter 1225.

[18] ICH Q2 (R1) (2005) Validation of Analytical Procedure: Text and Methodology. International Conference on Harmonization (ICH).

[19] Ruan, J., Tattersall, P., Lozano, R. and Shah, P. (2006) The Role of Forced Degradation Studies in Stability Indicating HPLC Method Development. American Pharmaceutical Review, 9, 46-53.

[20] Bakshi, M. and Singh, S. (2002) Development of Validated Stability-Indicating Assay Methods-Critical Review. Journal of Pharmaceutical and Biomedical Analysis, 28, 1011-1040.

[21] Carstensen, J.T. and Rhodes, C.T. (2000) Drug Stability Principles and Practices. 3rd Edition, Marcel Dekker, New York. 